\title{
Growth and Characterization of L - Isoluecine Doped Zinc (Tris) Thiourea Sulphate Single Crystals
}

\author{
A. David Kalaimani Raj ${ }^{1}$, S. Chidambaram ${ }^{2}$, R. Manimekalai ${ }^{3 *}$ \\ ${ }^{1,2,3}$ Department of Physics, A.V.V.M. Sri pushpam college, Poondi, Tamil Nadu, India. \\ *Corresponding Author: (R. Manimekalai) Maniabi64@gmail.com , Tel.: +919942544718
}

Available online at: www.isroset.org

Accepted: 27/Jun/2018, Online: 31/Aug/2018

\begin{abstract}
The L- Isoluecine doped Zinc Tris (thiourea) sulphate single crystals was grown by slow evaporation method. The unit cell parameters of the grown L- Isoluecine doped Zinc Tris (thiourea) sulphate single crystals are determined by single XRD. By FTIR analysis, the various functional groups of the grown L- Isoluecine doped Zinc Tris (thiourea) sulphate single crystal is determined. The optical properties of L-Isoleucine doped ZTS crystal is determined by UV-Vis spectral studies. The Florescence spectrum of L-Isoleucine doped ZTS crystal shows the strong emission in visible region at $555 \mathrm{~nm}$. The hardness of the material L-Isoleucine doped ZTS is measured by Vicker's Hardness method. The SHG efficiency of the L-Isoleucine doped ZTS was confirmed by Kurtz powder technique.
\end{abstract}

Keywords - Crystal growth, single XRD, FTIR, optical studies, Micro hardness, NLO studies

\section{INTRODUCTION}

Nowadays, the growth of crystal plays a vital role in modern technology. The recent development in various fields such as, optical communication and signal processing leads the researchers, interest and eminent focus in the growth of Non-linear optical crystals. The single crystals are widely used in semiconductors, optoelectronic industries and Photonics. Amino acids are the building blocks of proteins, contains amine $\left(\mathrm{NH}_{2}\right)$ and carboxyl $(\mathrm{COOH})$ functional groups. Mostly the amino acids are soluble in water and Dipolar in nature.

A zwitterion formerly called a dipolar ion is a molecule with two or more functional groups have at least one positive and one negative charge. The net charge of the entire molecule is electrically neutral, because the charges on the different functional groups balance each other. Zwitterions are also sometimes called inner salts. Amino acids are the best known example for Zwitterions; it is achieved by intermolecular acid - base reaction. When $\mathrm{H}^{+}$ion is transferred (i.e., Deprotonate) from an acid group to an amine group. L-Isoleucine is an amino acid contains an $\alpha$-amino group, an $\alpha$-carboxylic acid group, and a hydrocarbon side chain. It is a non-polar, uncharged aliphatic amino acid. L-Isoleucine is also a hydrophobic amino acid, that it repels the water molecules. L-Isoleucine used in the biosynthesis of proteins. Among many techniques, the slow evaporation technique is used to grow this crystal.

In this present work, the optically transparent good quality L-Isoleucine amino acid doped with Zinc sulphate and Thiourea single crystals were grown by slow evaporation method and the influence of L-Isoleucine on the properties of pure ZTS is described. The grown L-Isoleucine doped ZTS single crystals were undergoes various characterization techniques such as single X- Ray diffraction studies (XRD), Fourier transform infrared spectroscopy (FTIR), UV-Visible, Photoluminescence, Hardness and Non- linear optical (NLO) studies. Hereafter, we name the L-Isoleucine doped ZTS crystals as LIZTS.

\section{RELATED WORK}

In recent years, there has been an enormous report directed towards the development of novel single crystals using the chemical compounds such as Zinc Sulphate and Thiourea. The optical and electrical properties of Zinc tris thiourea single crystals are reported by M.Loganayaki, A.Senthil and P.Murugakoothan in the paper titled "Growth, Optical and Electrical Properties of zinc tris (thiourea) sulphate (ZTS) Single Crystals". Similarly, In the paper titled "Crystal Growth, Morphology, Spectral and Optical Studies of Tris (thiourea) Zinc Sulphate - Nonlinear Optical Material" by R. Muraleedharan, J. Ramajothi and M. Basheer Ahamed also reported the various characterizations 
such as optical, nlo and mechanical properties of ZTS. Further, novel single crystals are grown by adding L - Lysine amino acid with ZTS was reported by J. Thomas Joseph Prakash and M. Lawrence, entitled "Growth and Characterization of Pure and L-lysine Doped Zinc (TRIS) Thiourea Sulphate Crystals". Similarly, the mechanical and optical properties of L-Serine amino acid doped pure ZTS are reported in the paper named "Investigation on the properties of L-Serine doped Zinc tris (thiourea) sulphate crystal for NLO application" by F.Helen and G. Kanchana. In this present work, the L-Isoleucine amino acid is taken and it is doped with pure ZTS to grow a novel single crystal. The grown crystal is subjected to study its cell parameters, optical and mechanical properties. From the observed results, their characteristics are analyzed in this work.

\section{MATERIALS AND MeTHODS}

\section{Crystal growth}

The Zinc (tris) thiourea sulphate (ZTS) single crystals were made by dissolving the AR grade, Zinc sulphate and thiourea in deionized water in the stoichiometric molar ratio 1:3. In deionized water, the components are dissolved by stirring them thoroughly using a magnetic stirrer. The solution was very well liquefied by magnetic stirrer and the solution is kept undisturbed in a dust free atmosphere in a closed beaker. At room temperature, the ZTS crystals are grown by slow evaporation technique [1,2]. ZTS single crystals, was synthesized by the following reaction,

\section{$\left.\mathrm{ZnSO}_{4}+3 \mathrm{CS}\left(\mathrm{NH}_{2}\right)_{2} \longrightarrow \mathrm{Zn}\left[\mathrm{CS}\left(\mathrm{NH}_{2}\right)_{2}\right)_{3}\right] \mathrm{SO}_{4}$}

After 15 - 20 days, good quality of ZTS single crystals was harvested. The grown crystals were stable and transparent. To grow the LIZTS single crystals, 0.1 and 0.3 Mole L-Isoleucine amino acid was added to the solution of ZTS. The Single crystals of LIZTS with good shape and size were harvested in the same period. The figures 1(a), 1(b) and 1(c) shows, the photographs of the grown pure, $0.1 \mathrm{M}$ and 0.3 Mole L-Isoleucine doped ZTS crystals.

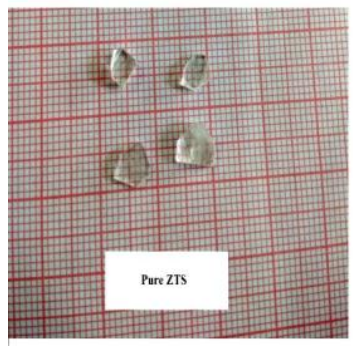

Figure - 1 (a). pure ZTS

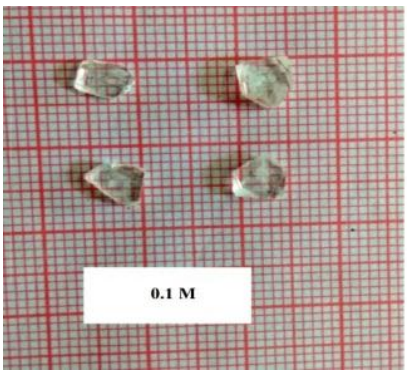

Figure - 1 (b). 0.1 M LIZTS

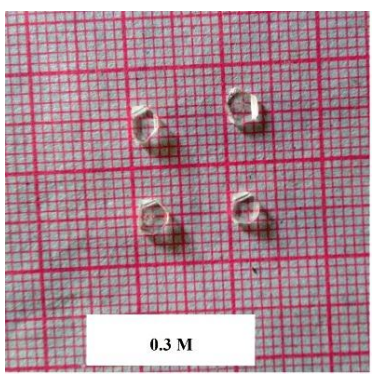

Figure - 1 (c). 0.3 M LIZTS

\section{RESUlTS AND DISCUSSION}

The grown crystals are subjected to various characterization techniques. The grown crystals of pure ZTS and L-Isoleucine doped ZTS was confirmed by single crystal $X$-ray diffraction analysis using ENRAF NONIUS CAD4 diffractometer. The Various functional groups are identified by using PERKIN ELMER RX1 Fourier Transform Infrared spectrophotometer in the range of $400-4000 \mathrm{~cm}^{-1}$. The optical Characteristics of the crystal were analyzed in the range of 190 and $1100 \mathrm{~nm}$ using LAMBDA-35 UV-Vis spectrometer. The Vickers hardness measurement was made on the crystal using Shimadzu (Japan) HMV-2 hardness tester.The NLO efficiency of the grown sample confirmed Nd: YAG laser as the source. The fluorescence spectrum was recorded by VARIAN Cary Eclipse Fluorescence Spectrophotometer employing 150 Watts Xenon arc discharge lamp as the excitation source.

\subsection{Single crystal $X$-ray diffraction analysis}

The single crystal X-ray diffraction is a nondestructive analytical technique which yields detailed information about the internal lattice of crystalline substances, unit cell dimensions and atomic positions inside the unit cell from a very small amount of material. To determine the lattice parameters and volume of the grown single crystals of Pure and LIZTS crystals were subjected to single crystal X-ray Diffraction analysis using Bruker Smart 
Apex2 single crystal X-ray Diffractometer. The Table 1 below gives the lattice parameters values of LIZTS [2]. From the Table 1, it is clear that there is no change in the crystal system. The change in the Unit cell dimension and volume indicates the inclusion of L-Isoleucine in ZTS lattices.

Table 1: Unit cell parameters of pure ZTS and LIZTS

\begin{tabular}{|c|c|c|c|c|c|c|c|}
\hline $\begin{array}{c}\text { S. } \\
\text { No }\end{array}$ & Crystal & $\mathbf{a}$ & $\mathbf{b}$ & $\mathbf{c}$ & $\boldsymbol{\alpha}=\boldsymbol{\beta}=\boldsymbol{\gamma}$ & $\begin{array}{c}\text { Volume } \\
\left(\mathbf{A}^{\circ}\right)\end{array}$ & $\begin{array}{c}\text { System } \\
\left(\mathbf{A}^{\circ}\right)\end{array}$ \\
\hline 1. & ZTS & 7.79 & 11.14 & 15.512 & $\left.90^{\circ}\right)$ & 1341.6 & Orthorhombic \\
\hline 2. & LIZTS & 7.91 & 11.31 & 16.00 & $90^{\circ}$ & 1441 & Orthorhombic \\
\hline
\end{tabular}

\subsection{FTIR Analysis}

The Fourier transform infrared spectral analysis is a technique in which almost all functional groups in a molecule absorb characteristic frequencies. The FTIR analysis was carried out using Alpha Bruker FTIR Spectrometer by $\mathrm{KBr}$ pellet technique in the range of $400-$ $4000 \mathrm{Cm}^{-1}$. The FTIR spectra of Pure ZTS, $0.1 \mathrm{M}$ and $0.3 \mathrm{M}$ LIZTS are shown in the Figure 2. The N-H stretching, at peaks $3310,33.09$ and $3308 \mathrm{~cm}^{-1}$ due to the presence of primary amine $[4,5]$. The peaks at 714 and $716 \mathrm{~cm}^{-1}$ is due $\mathrm{C}=\mathrm{S}$ symmetric stretching vibrations $[2,3,4]$. The various functional groups and the relevant wave numbers are represented in Table 2.

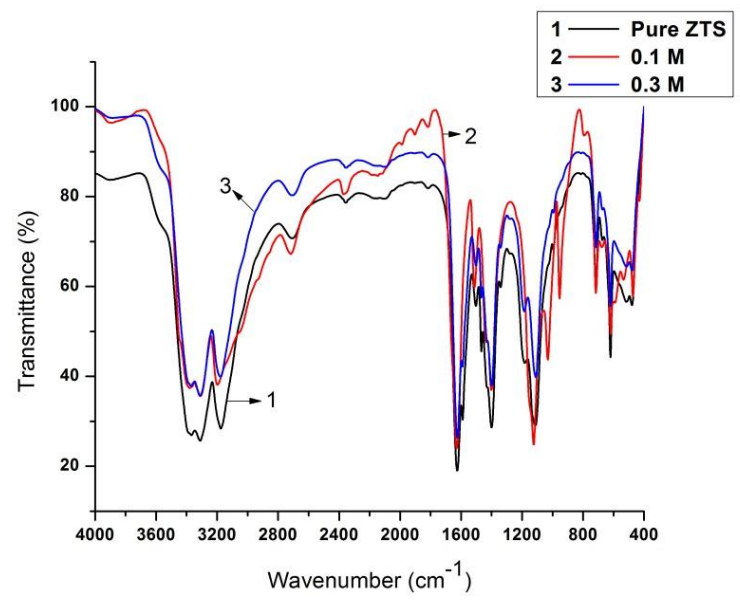

Figure - 2. FTIR Spectrums of ZTS and LIZTS

Table 2: Frequency assignments of ZTS, $0.1 \& 0.3 \mathrm{M} \operatorname{LIZTS}\left(\mathrm{cm}^{-1}\right)$

\begin{tabular}{|c|c|c|c|l|}
\hline & ZTS & 0.1 M LIZTS & 0.3 M LIZTS & \multirow{2}{*}{ Assignments } \\
\cline { 2 - 4 } S. & Wavenumber & Wavenumber & Wavenumber & \\
\hline 1. & 3367 & 3379 & 3370 & O-H stretching \\
\hline 2. & 3310 & 3309 & 3308 & N-H stretching \\
\hline 3. & 1625 & 1628 & 1624 & C=C stretching \\
\hline 4. & 1400 & 1401 & 1400 & C=S asymmetric stretching \\
\hline 5. & 1112 & 1124 & 1122 & C-N stretching \\
\hline 6. & 714 & 716 & 714 & C=S symmetric stretching \\
\hline 7. & 620 & 618 & 620 & N-C-S asymmetric stretching \\
\hline 8. & 478 & 472 & 478 & C-S-N symmetric bending \\
\hline
\end{tabular}

\subsection{UV - Visible Spectral Analysis}

The UV-VIS spectrometry is one of the oldest instrumental techniques of optical analysis of a sample. UV-VIS spectrum results from the interaction of electromagnetic radiation in the UV-VIS region with molecules, ions or complexes. The study of Optical Transmissions of the grown crystal is done by using Perkin Elmer Lambda 35 UV-Visible spectrophotometer in the wavelength range of 190 to $1100 \mathrm{~nm}$. From the absorption spectra, the grown crystals have lower cut off wavelengths of around $198.4 \mathrm{~nm}$ for Pure ZTS, 193.40 and $198.30 \mathrm{~nm}$ for $0.1 \& 0.3$ Mole of LIZTS respectively [1]. The absorption spectra of pure ZTS, 0.1 and 0.3 Mole LIZTS are shown in the following Figure 3 (a). Similarly, the transmittance spectra of pure ZTS, 0.1 and 0.3 Mole LIZTS are shown in the following Figure 3 (b). The Energy gap is calculated for 0.1 and 0.3 Mole LIZTS are shown in the Figure 4. The optical band gap energy was found to be $2.00 \mathrm{eV}$ for 0.1 mole LIZTS and $2.3 \mathrm{eV}$ for 0.3 mole LIZTS from Tauc's plot $[3,4]$ as shown in Figure 4. On further improvisation of growth, characterization, it may be suitable for optoelectronic devices.

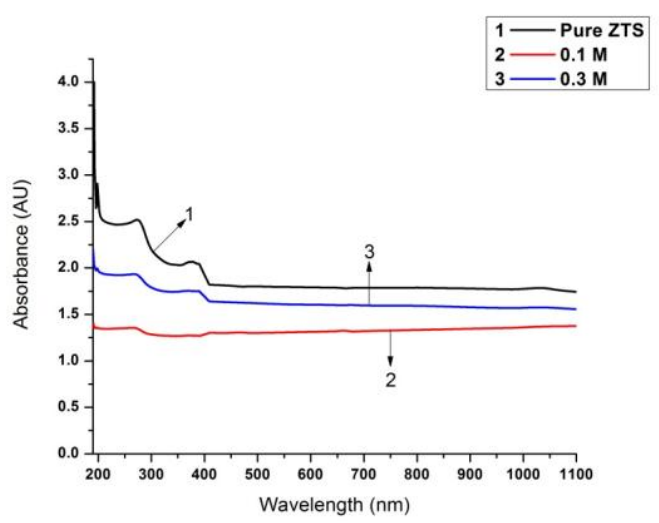

Figure - 3(a). Absorption spectrums of ZTS and LIZTS 


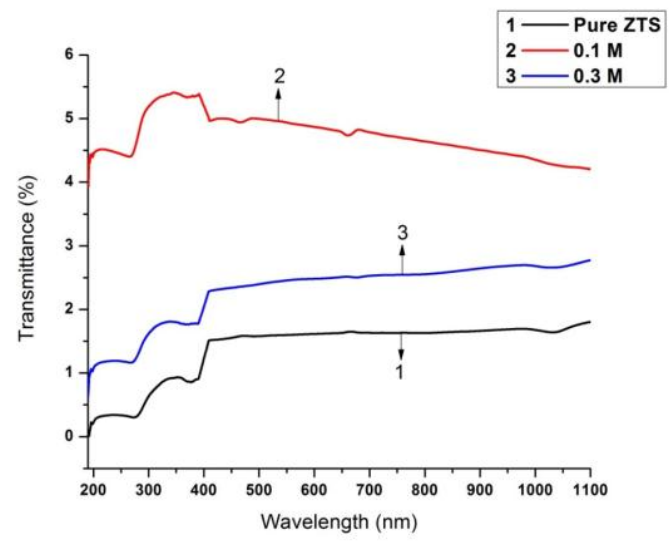

Figure - 3(b). Transmittance spectrums of ZTS and LIZTS

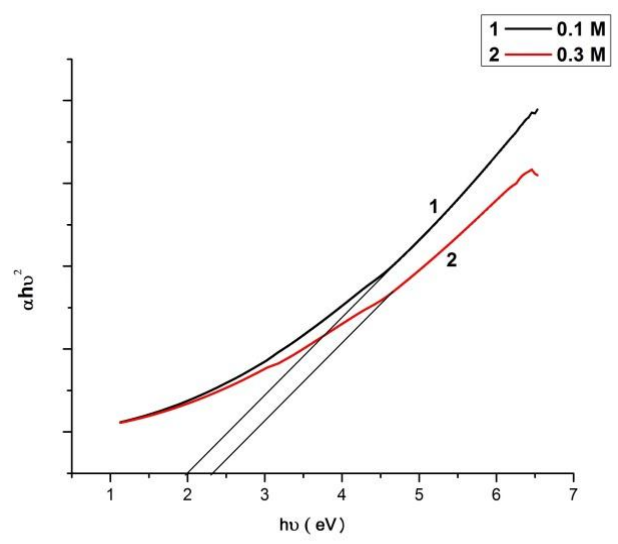

Figure - 4. Tauc's Plot of LIZTS

\subsection{Vicker's Hardness Test}

The Mechanical strength of the materials plays a key role in the device fabrication. Vickers hardness is one of the important deciding factors in selecting the processing (cutting, grinding and polishing) steps of bulk crystal in fabrication of devices based on crystals. The Vicker's hardness test is said to be a more reliable method of hardness measurement. Hardness studies on the grown crystals of $0.1 \mathrm{M}$ doped ZTS and $0.3 \mathrm{M}$ doped ZTS were carried out by a static indentation test at room temperature using a Leitz Wetzlar Vickers micro hardness tester fitted with a Vickers diamond pyramidal indenter attached to an incident light microscope. Several indentations were made on the crystal by varying the loads from $25 \mathrm{gm}$ to $100 \mathrm{gm}$ and the hardness number $\left(\mathrm{H}_{\mathrm{v}}\right)$ was determined. The indentation time was kept as $15 \mathrm{~s}$ for all the loads. As micro cracks were developed on the crystal surface at higher loads, the maximum applied load was limited to $100 \mathrm{gm}[2,4]$.

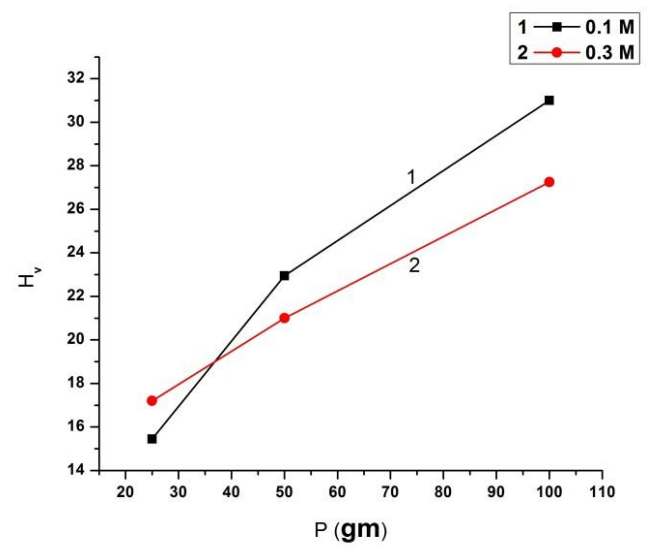

Figure - 5 (a). Load P Vs Hardness of LIZTS

The hardness number was calculated using the relation,

$$
\mathrm{H}_{\mathrm{v}}=\frac{(1.8544 * \mathrm{P})}{\mathrm{d}^{2}} \mathrm{~kg} / \mathrm{mm}^{2}
$$

where, $\mathrm{H}_{\mathrm{v}}$ is the Vickers micro hardness number, $\mathrm{P}$ is the applied load in $\mathrm{kg}$ and $\mathrm{d}$ is the diagonal length of the indentation impression in the micrometer. A graph has been plotted between hardness number $\left(\mathrm{H}_{\mathrm{v}}\right)$ and applied load $(\mathrm{P})$. Variation of the hardness number $\left(\mathrm{H}_{\mathrm{v}}\right)$ with the applied load (P) for $0.1 \mathrm{M}$ and $0.3 \mathrm{M}$ doped ZTS are shown in Figure 5(a). From the Figure 5 (a), it is clear that $\mathrm{H}_{\mathrm{V}}$ increases with an increase in the load. It reveals that, if the applied load increases then the hardness number also increases. This phenomenon is known as reverse indentation size effect (RISE).

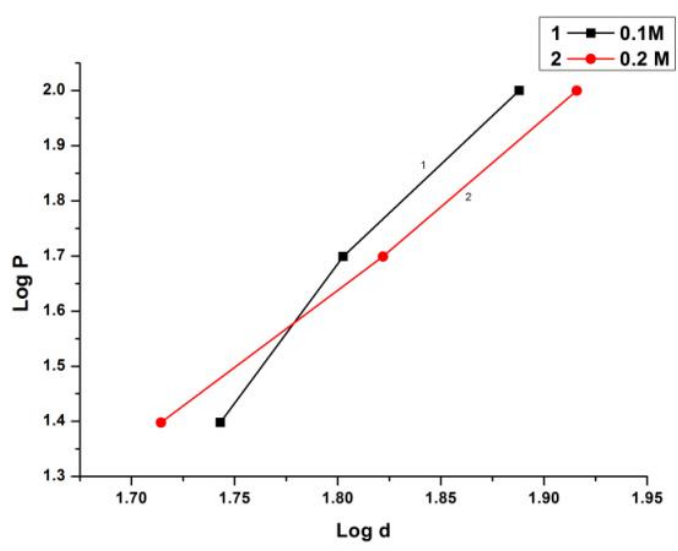

Figure - 5 (b). Log d Vs Log P of LIZTS 
The Meyer's index number was calculated from the Meyer's law, which relates the load and indentation diagonal length.

$$
\begin{gathered}
\mathrm{P}=\mathrm{k} \mathrm{d}^{\mathrm{n}} \\
\log \mathrm{P}=\log \mathrm{k}+\mathrm{n} \log \mathrm{d}
\end{gathered}
$$

where, $k$ is the material constant and $n$ is the Mayer's index or work-hardening coefficient. By plot a graph, $\log \mathrm{P} v s \log$ $\mathrm{d}$, for the grown crystals, as shown in Figure 5(b), the value of ' $n$ ' was determined. The slope of the graphs, will give the work hardening index (n) which is found to be 5.05 and 2.797 for $0.1 \& 0.3 \mathrm{M}$ of LIZTS [3, 4].

\subsection{Fluorescence studies}

The grown LCZTS single crystals are subjected to fluorescence studies using fluorescence spectrometer. The spectrum recorded by the emission of photo generated minority carriers is a direct way to measure the band gap energy. The Figure 6 shows the emission spectrum of Pure and LIZTS single crystals. The peak at $576 \mathrm{~nm}$ is observed in the emission spectrum of pure ZTS. Similarly, the peaks at 550 and $555 \mathrm{~nm}$ were observed in the emission spectrum of 0.1 and $0.3 \mathrm{M}$ of LIZTS [7].

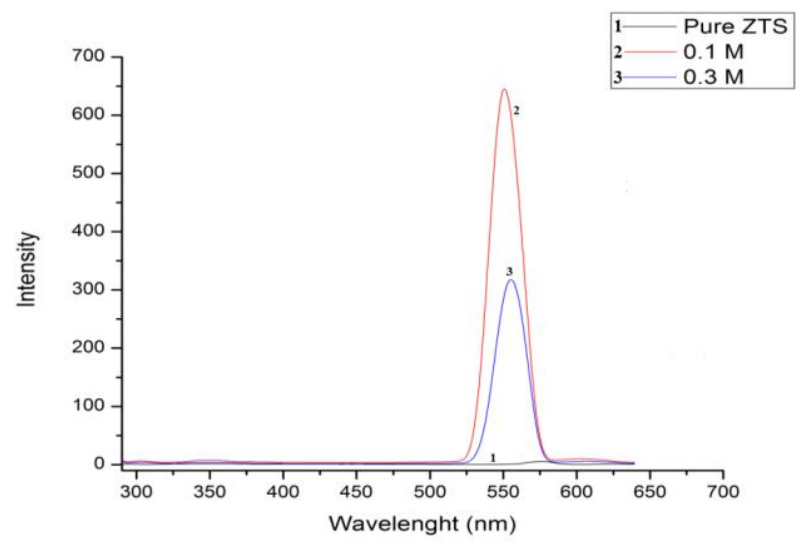

Figure - 6. Fluorescence studies of pure ZTS and LIZTS

\subsection{NLO Studies}

Second harmonic generation (SHG) is a nonlinear optical process. It is otherwise called as Frequency Doubling. By relate the same frequency Photons with a nonlinear material and produce new photons. The new photons that produced have double frequency to that of the initial photons. Second harmonic generation (SHG) for the powder of grown LIZTS has been carried out by using Kurtz powder technique [1]. Powder samples illuminated by using Q-switched Nd: YAG laser emitted the fundamental wavelength of $1064 \mathrm{~nm}$. The second harmonic generation was confirmed by the emission of green radiation $(532 \mathrm{~nm})$ in the repetition rate of $10 \mathrm{~Hz}$ and pulse width of $6 \mathrm{~ns}$ [9]. From the observed results, conversion efficiency of LIZTS is 0.2114 times to that of KDP [4].

\section{CONCLUSION AND Future SCOPE}

The LIZTS single crystals were grown by slow evaporation technique in a period of three weeks. The single XRD analysis confirms that, the grown crystals belong to the orthorhombic system. The various functional groups and its vibrational modes have been analyzed by the FTIR spectrum. The absorption in the entire visible range and the lower cut-off wavelength for 0.1 and $0.3 \mathrm{M}$ of LIZTS is $190 \mathrm{~nm}$ and $198 \mathrm{~nm}$ respectively. The transmittance property is also good, so it is suitable for optoelectronic devices. From the uv absorption study, the band gap energy was found to be $2.00 \mathrm{eV}$. The Vicker's micro hardness was calculated, to study the mechanical stability of the grown crystals. From the Hardness results, it is seen that, the grown LIZTS crystals are soft materials. The fluorescence spectrum of the grown LIZTS crystal shows the green emission $(555 \mathrm{~nm})$. The non-linear nature of the grown crystal is analyzed with Kurtz and Perry Powder technique, the SHG efficiency was found to be 0.2114 times that of KDP. It confirms the NLO property of the grown crystal. By improving the grown crystal, it may be used in optoelectronic devices.

\section{ACKNOWLEDGMENT}

The authors thank Dr.G.V.Vijayaraghavan, Associate Professor, Department of Physics, B.S.Abdur Rahman Crescent Institute of Science and Technology, Chennai, India for providing SHG facilities. The authors acknowledge St. Joseph's College, Trichy, India for spectral facilities. The authors gratefully acknowledge the Sophisticated Analytical Instrument Facility, Indian Institute of Technology Madras, Chennai, India, for the XRD studies.

\section{REFERENCES}

[1]. P. Malliga and C. Senthamilselvi, "Growth and Characterization of alanine doped zinc tris thiourea sulphate single crystal”, RJC, Vol. 9, No. 2, PP. 144 - 148, 2016.

[2]. J. Thomas Joseph Prakash and M. Lawrence, "Growth and Characterization of Pure and L- lysine Doped Zinc (TRIS) Thiourea Sulphate Crystals", International Journal of Computer Applications, Volume 8- No.3, PP. 0975-8887, 2010.

[3]. R. Muraleedharan, J. Ramajothi \& M. Basheer Ahamed, “Crystal Growth, Morphology, Spectral and Optical Studies of Tris (thiourea) Zinc Sulphate - Nonlinear Optical Material”, Indian Journal of Science and Technology, Vol 8(S7), PP. 165-170, 2015. 
[4]. F.Helen \& G.Kanchana, "Investigation on the properties of $L$ Serine doped Zinc Tris Thiourea sulphate Crystal for NLO application", Indian Journal of Pure \& Applied Physics, Vol. 52, PP. 821-828, 2014.

[5]. Hiral Baraniya \& Anand Panchal, "Growth \& Characterization of ZINC (Tris) Thiourea Sulphate (ZTS) Single Crystals", International Journal of Engineering and Technology, Vol. 3, Issue. 4, PP. 2464 - 2467, 2016.

[6]. S.Ariponnammal, S.Chandrasekaran \& C.Sanjeeviraja, "Low Temperature Photoluminescence Study on Zinc tris Thiourea sulphate Single Crystal", Digest Journal of Nanomaterials and Biostructures, Vol. 7, No. 3, PP. 947 - 957, 2012.

[7]. Kiran T. Rathod, I.B. Patel1, C.F. Desai and Y.H. Gandhi, "PhotoLuminescence Studies of Pure and Doped ZTS Single Crystals Grown by Single Diffusion Technique”, International Journal of Luminescence and Applications, Vol. 5, No. 1, PP. 86-88, 2015.

[8]. M. Loganayaki, A. Senthil \& P. Murugakoothan, "Growth, Optical and Electrical Properties of zinc tris (thiourea) sulphate (ZTS) Single Crystals", International Journal of Computer Applications, Vol. 72, No. 1, PP. 0975 - 8887, 2013.

[9]. M. Lawrence \& J. Felicita Vimala, "Growth and characterization of pure and L-Alanine doped Zinc Tris-thiourea Sulphate (ZTS) single crystals", International Journal of Engineering Science and Innovative Technology, Vol. 4, Issue. 2, PP. 210 - 218, 2015.

[10]. A. Puhal Raj and C. Ramachandra Raja, " The Effect of Phosphate Mixing on Structural, Spectroscopic, Mechanical and Optical Properties of Zinc tris Thiourea Sulphate (ZTS) Single Crystals", Journal of Minerals \& Materials Characterization \& Engineering, Vol. 11, No.5, PP. 471-478, 2012.

[11]. P. Dhanya and Fernando Loretta, "Growth and Studies on Lithium Sulphate Doped Zinc Tris Thiourea Sulphate Single Crystals", international journal for research in emerging science and technology, volume-2, issue-12, PP. 45-49, 2012.

[12]. S. Gopinath1, R. Palanivel1 \& R. Rajasekaran, "Growth and Studies of Pure and Cadmium Chloride-Doped Zinc Tris-Thiourea Sulphate (CCZTS) Crystals", International Journal of Pure and Applied Sciences and Technology, vol.1 (2), PP. 104-113, 2010.

[13]. N.Balasundari \& P.Selvarajan, "Studies on Nucleation, Growth and Characterization of L-Leucine Doped ZTS Crystals", IOSR Journal of Applied Physics, PP. 39-45, 2017.

[14]. P. Suveetha, T. Sathya, S. Sudha \& M.B. Jessie Raj, "Growth and Studies of Halides doped Zinc Tris-Thiourea Sulphate (HZTS) Crystals", International Journal of Advancements in Research \& Technology, Volume 1, Issue 5, PP. 1-7, 2012.

[15]. K.Senthil Kannan, S.Gunasekaran \& KA.Seethalakshmi, "Growth and Spectroscopic studies of Pure and L-Proline doped ZTS crystal (with Taxol)", International Journal of Scientific \& Engineering Research, Volume 4, Issue 2, PP. 1-5, 2013.

[16]. P. Dhanya and Fernando Loretta, "Growth and Studies on Lithium Sulphate Doped Zinc Tris Thiourea Sulphate Single Crystals", International Journal for Research in Emerging Science and Technology, volume-2, issue-12, PP. 46-49, 2015.

\section{AUTHORS PROFILE}

Dr. R. Manimekalai pursed M.Sc., M.Phil., and Ph.D from Bharathidasan University, Tiruchirappalli in 1988, 1989 and 2014. Presently working as an Associate professor of Physics, A.V.V.M. Sri Pushpam College, Poondi, Thanjavur-613 503, Tamil Nadu, India. Having 29 years of teaching and research experience in UG, PG and M.Phil., level. Acting as research advisor in physics from the year 2016 onwards in A.V.V.M. Sri Pushpam College (Autonomous), Poondi, Thanjavur (affiliated to Bharathidasan University). Published more than 12 research papers in reputed, peer reviewed, citation indexed international journals (Elsevier, Springer, Science direct) and international level conference. At present, guiding eight Ph.D and six M.Phil research Scholars.

Mr. A. David Kalaimani Raj pursed Bachelor of Science, Master of Science and M.Phil., in A.V.V.M. Sri Pushpam College, Poondi, Thanjavur,Tamil Nadu, India and Bharathidasan University, Tiruchirappalli respectively, in 2002, 2004 and 2005. He is currently pursuing $\mathrm{Ph} . \mathrm{D}$ as a part- time research scholar in the A.V.V.M. Sri Pushpam College (Autonomous), Poondi, Thanjavur (affiliated to Bharathidasan University) and currently working as an Assistant professor in Physics, Bharathidasan University model college, Aranthangi, Pudukkottai (Dt), Tamil Nadu, India. His main research work focuses on Material science. He has 15 years of teaching and research experience in UG and PG level.

Mr. S. Chidambaram pursed Bachelor of Science and Master of Science, in Government Arts College, Udhagamandalam, Tamil Nadu, India and Bharathiar university Coimbatore respectively, in 2011, 2014, and M.Phil., in A.V.V.M. Sri Pushpam College, Poondi, Thanjavur, Tamil Nadu, India and Bharathidasan University, Tiruchirappalli respectively, in 2016. He is currently pursuing Ph.D as a Full- time research scholar in the A.V.V.M. Sri Pushpam College (Autonomous), Poondi, Thanjavur (affiliated to Bharathidasan University) Tamil Nadu, India. His main research work focuses on Material science. 